\title{
Internet Domain Names in China
}

Articulating Local Control with Global Connectivity

\section{Séverine Arsène}

\section{OpenEdition}

\section{Journals}

Electronic version

URL: http://journals.openedition.org/chinaperspectives/6846

DOI: 10.4000/chinaperspectives.6846

ISSN: 1996-4617

\section{Publisher}

Centre d'étude français sur la Chine contemporaine

\section{Printed version}

Date of publication: 1 December 2015

Number of pages: $25-34$

ISSN: 2070-3449

\section{Electronic reference}

Séverine Arsène, "Internet Domain Names in China », China Perspectives [Online], 2015/4 | 2015,

Online since 01 January 2017, connection on 28 October 2019. URL : http://journals.openedition.org/ chinaperspectives/6846; DOI : 10.4000/chinaperspectives.6846 


\title{
Internet Domain Names in China
}

\author{
Articulating Local Control with Global Connectivity
}

SÉVERINE ARSĖNE

\begin{abstract}
This article aims at documenting the implementation of the Domain Name System in China, in coordination and in tension with the global Domain Name System since the end of the 1980s with the Chinese country-code top-level domain ".cn," and more recently with the creation of Chinese-language domain names such as “.中国” and “.中文网." It puts into perspective the notion of "digital sovereignty" by analysing the role of the DNS in the "localisation" of online content as part of the censorship system. It further shows that although Chinese representatives have always been very critical of the existing architecture and management of the DNS on the global stage, their attitude has evolved from de facto, bottom-up participation and protection of their interests to a more confident and assertive behaviour, as the growth of the Chinese Internet has put them in a more dominant position.
\end{abstract}

KEYWORDS: China, Internet, Domain name system, CNNIC, ICANN, digital sovereignty, localisation, Great Firewall.

T he Internet is often presented as an ensemble of connected networks without any form of hierarchy - a totally horizontal system connecting individual machines to each other. However, it is much more structured and hierarchical than it seems because of the characteristics of its "logical" architecture, and the technical norms and standards that enable the smooth circulation of digital content on these networks.

In particular, there needs to be one single addressing system to identify the localisation of every device connected to the network. For this purpose, every connected device is attributed with a unique number, or IP address. For example, the IP address of the French Centre for Research on Contemporary China's website server is 203.90.226.135. IP addresses are difficult to understand and memorise by (human) Internet users, so to facilitate the identification of a website's location, websites are generally registered under a domain name, such as "cefc.com.hk." The Domain Name System (DNS) functions as a directory that associates a domain name with the IP address of the website's server. It thus plays a crucial role in routing Internet traffic to the right location.

Because these names and numbers require global coordination, they are called "critical resources" of the Internet. (1) The allocation of IP addresses and domain names is currently managed through a global set of institutions coordinated from the United States by the Internet Corporation for Assigned Names and Numbers (ICANN). The distribution of domain names and the maintenance of accurate and up-to-date records globally involve hundreds of public and private institutions, which run thousands of servers around the world for this sole purpose.

Domain names are increasingly used as marketing tools that serve to attract audiences through a logical, understandable, appealing name. They are important to businesses, governments, NGOs, independent journalists, and individuals alike for creating a stable identity online. However they can be squatted on, hijacked, faked, or even censored. As a consequence, the operation of the DNS around the world is an essential though largely unknown political stake that involves issues of cybersecurity, intellectual property, and free speech, to mention but a few.

For this reason, the Domain Name System has become an essential part of both the domestic and international Internet policy of the Chinese gov- ernment. Ever since the early days, Chinese people and administrations in charge of the management of the Chinese Domain Name System were caught in an apparent contradiction. On the one hand, participation in the global Domain Name System is indispensable to the connection of the Chinese Internet with the global network, and thus to its actual qualification as part of the "Internet" rather than a separate "Intranet." On the other hand, the Chinese government routinely uses domain names and IP addresses to block access to foreign websites as part of the so-called Great Firewall, one of the most infamous aspects of Internet censorship in China. It is an early example of a more general tendency among countries to tamper with the universality of DNS records, to "localise" Internet content, or to selectively restrict access to certain websites in the name of national sovereignty. This tension between the need to achieve global connectivity and the will to maintain control was also reflected in China's critical position towards the institutions in charge of the DNS globally, such as ICANN, while they always maintained a certain level of participation in critical discussions and working groups.

This article aims at documenting the implementation of the Chinese Domain Name System in coordination and in tension with the global Domain Name System. The first part explains what the Domain Name System is and how it is an essential element of the Chinese government's efforts to control online information. The second part is a chronological account of the implementation of the Chinese Domain Name System. While the technological development of the Chinese Domain Name System is largely due to the participation and cooperation of Chinese engineers in international networks all through the 1990s and 2000s, China's political leaders put more emphasis on the affirmation of "cyber-sovereignty" by centralising regulatory powers domestically and by calling for more intergovernmental governance on the international stage. In the third part, I focus on the specific case of the development of Chinese-character domain names in the 2000s, which further exemplifies how China has managed to defend its interests through the consolidation of its domestic Domain Name System while tak-

1. Laura DeNardis, The Global War for Internet Governance, New Haven, Yale University Press, 2014, Chapter 2: "Controlling Internet Resources"; Milton L. Mueller, Networks and States: The Global Politics of Internet Governance, Cambridge, MA, and London, MIT Press, 2010, pp. $231 \mathrm{ff}$. 
ing an active part in the global technical and governance debates that matter most to it. As showed in the fourth part, in more recent years this enhanced participation of Chinese leaders in Internet governance institutions such as ICANN also reveals a more confident and assertive behaviour, as the growth of the Chinese Internet has put them in a more dominating position.

The material used in this enquiry is composed of press articles and official announcements, regulatory documents, official websites, and interviews conducted in Beijing in November 2014 with current and former members of related institutions such as the Chinese Academy of Sciences, ICANN, the Chinese Internet Network Information Center, and the Ministry of Industry and Information Technologies.

\section{A localised Internet: Information control and the Domain Name System}

\section{Domain names and the Great Firewall of China}

The DNS is politically important for many reasons, not least because it is one of the technical tools used to block access to foreign websites through their domain name or IP address. This is done through Internet service providers (ISPs), such as China Telecom and China Unicom, at various levels, including backbone networks and international interconnections, and using a variety of technologies. (2) The authorities provide ISPs with lists of IP addresses and domain names that they must block. (3) When an Internet user types a blocked website's address into his browser, he will then be routed by ISPs to the wrong website or to an error page, typically "Error 404 Page Not Found."

This type of blocking through the DNS system can also have intentional or unintentional side effects. There are many cases of "overblocking," where entire blog platforms (or other content platforms) are blocked as the result of the targeting of a single page. (4) More strikingly, occasional errors in the manipulation of DNS records can lead to embarrassing episodes where a large portion of Chinese Internet traffic is mistakenly routed to overseas servers hosting the websites of dissident organisations, causing the crash of these servers and a major disruption of Internet service for affected users in China. ${ }^{(5)}$

There are various ways to access a website with a blocked domain name. First, one can still directly input the numerical IP address of the website, at least until the IP address is blocked as well, in which case it may be possible to view the website via a "proxy" server; that is, a computer situated abroad, which forwards the content of the requested website without showing its domain name or IP of origin. This works until this particular proxy is identified and blacklisted as well. An even more efficient way is to use a "virtual private network" (VPN), which on top of connecting the user with a server abroad also encrypts content. Again, this comes down to a cat-and-mouse game until the VPN is also blocked.

DNS blocking is only one aspect of a much broader array of censorship technologies used by China, and in fact, is not even the most powerful one ${ }^{(6)}$ compared with keyword filtering, which applies to all content circulating in and outside of China, and with the control of content that is exercised by all self-expression platforms such as Weibo or blogs. But it is one of the most visible and symbolical tools as seen from abroad, because it potentially enables China to "cut off" the country from the global Internet. This is why the Chinese Internet censorship system is often nicknamed the "Great Fire- wall" (7) of China, symbolically representing a virtual "fence" around the country, or compared to a giant "Intranet." This metaphor may in fact be too strong, since the blocking's very purpose is to enable selective access to the global Internet rather than blocking it altogether.

China is often accused of using blocking against foreign tech companies such as Google or Facebook to favour the development of local champions. ${ }^{(8)}$ Indeed, this blocking poses a dilemma to foreign companies: either they comply with Chinese censorship laws and hide certain content to Chinese users, with huge consequences in terms of reputation and trust at home, or they risk completely losing the opportunity to tap into the Chinese market. (9) The decision by Google to finally leave the Chinese market in 2010 was a case in point. ${ }^{(10)}$

In that regard it must be noted that the use of domain name blocking through local ISPs is not a specificity of China, although the country champions it. Many countries, including democratic countries, have adopted such measures in the name of protecting their citizens against content deemed illegal (copyright, ${ }^{(11)}$ child pornography, etc.) or morally unacceptable (religion, ${ }^{(12)}$ pornography, ${ }^{(13)}$ etc.). The specificities of China and other authoritarian countries in that regard may be the extensive focus on blocking political websites, the particularly blurry legal framework and opaque deci-

2. For a technical overview, see Charles Guangchao Feng and Steve Zhongshi Guo, "Tracing the Route of China's Internet Censorship: An Empirical Study," Telematics and Informatics, Vol. 30, No. 4, November 2013, pp. 335-345; for a more read-friendly explanation, see James Fallows, "'The Connection Has Been Reset'," The Atlantic, 1 March 2008, www.theatlantic.com/magazine/ archive/2008/03/-the-connection-has-been-reset/306650/?single_page=true (all URLs accessed on 13 March 2015).

3. The website GreatFire monitors censored websites. See https://en.greatfire.org/faq

4. In 2014, the activist organisation GreatFire proposed to push a circumvention strategy designed to raise the cost of DNS blocking for the censors by hosting censored content on encrypted cloud computing services. Because these services store content on collectively-used servers, the Chinese authorities would have to cut access to all content hosted on the same platform as collateral damage. While GreatFire's bet was that the Chinese authorities would refrain from cutting Chinese Internet users' access to commercially essential services, the Chinese censors made their point by blocking EdgeCast, an important cloud platform, simultaneously blocking access to thousands of websites, including some of Sony Mobile's services and some features of the web browser Firefox. See James Griffiths, "China Blocks Thousands More Websites as 'Great Firewall' Targets Cloud Services," South China Morning Post, 18 November 2014, www.scmp.com/news/china/ article/1642977/china-blocks-thousands-more-websites-great-firewall-targets-cloud.

5. Nicole Perlroth, "Big Web Crash in China: Experts Suspect Great Firewall," Bits - NYTimes.com, 22 January 2014, http://bits.blogs.nytimes.com/2014/01/22/big-web-crash-in-china-experts-suspect-great-firewall/?_r=0; Xinhua News agency does not mention the Great Firewall. "Chinese Experts Demand More DNS Protection," Xinhuawang, 22 January 2014, http://news. xinhuanet.com/english/china/2014-01/22/c_133065951.htm.

6. See OpenNet Initiative, "China," 15 June 2009, http://opennet.net/research/profiles/china.

7. Geremie Barmé and Sang Ye, "The Great Firewall of China," Wired, June 1997, http://archive. wired.com/wired/archive/5.06/china.html.

8. Michael A. Santoro and Wendy Goldberg, "Fair Trade Suffers When China Censors the Internet. It's Not Just a Human Rights Issue," The Huffington Post, 2 September 2009, http://www.huffingtonpost.com/michael-a-santoro-and-wendy-goldberg/chinese-internet-censorsh_b_156212.html.

9. Paul Mozur and Vindu Goel, "To Reach China, LinkedIn Plays by Local Rules," NYTimes.com, 5 October 2014, www.nytimes.com/2014/10/06/technology/to-reach-china-linkedin-plays-by-localrules.html.

10. Jyh-An Lee, Ching-Yi Liu, and Weiping Li, "Searching for Internet Freedom in China: A Case Study on Google's China Experience," Cardozo Arts \& Entertainment Law Journal, Vol. 31, No. 2, 1 April 2013.

11. For example, many countries block access to The Pirate Bay, a file-sharing website often used to illegally download copyrighted content. See in France: Marc Rees, "Pourquoi et comment The Pirate Bay sera bloqué en France" (Why and How Will The Pirate Bay Be Censored in France?), Next INpact, 5 December 2014, www.nextinpact.com/news/91265-pourquoi-the-pirate-bay-etses-miroirs-seront-bloques-en-france.htm.

12. Ali Sethi, "Banistan: Why Is YouTube Still Blocked in Pakistan?", The New Yorker, 7 August 2013, www.newyorker.com/tech/elements/banistan-why-is-youtube-still-blocked-in-pakistan.

13. In India: Jayadevan PK and Neha Alawadhi, "Government Asks Internet Service Companies to Block Pornography Sites, Upgrade Systems," Economic Times, 11 November 2014, http://articles.economictimes.indiatimes.com/2014-11-11/news/55990473_1_internet-service-providers-internet-freedom-blocking-internet. 
sion-making, as well as the absence of appeal, all of which come down to the absence of true rule of law.

Nonetheless this global pattern of domain name blocking is part of a strong trend towards more "localisation" of the Internet for a variety of legal, cultural, and marketing reasons. ${ }^{(14)}$ Alongside blocking measures, more and more governments are calling for local storage of data out of cybersecurity concerns. ${ }^{(15)}$ Many companies fear the prosecution of their overseas employees for hosting content considered blasphemous, pornographic, or revisionist in various countries, and have decided to censor content according to specific countries. ${ }^{(16)}$ Copyright issues also motivate content providers to limit the availability of cultural products, such as TV programs, to one specific country. In addition, for more efficiency, most services adapt their webpages to the viewers' supposed preferences in terms of language, currency, or tastes. As a result, Internet users do not automatically have access to a single global Internet; in other words, the Internet is displayed in a different way to each individual, sometimes without his knowledge or consent.

Some Internet rights defence organisations and activists have criticised this localisation trend as a threat to "break" the Internet, because its value lies precisely in the openness and equal treatment of users and data ("net neutrality"). (17) On the other hand, a recent editorial of the Chinese Global Times praised localisation as "inevitable," for "if the Internet is truly global, it has to strike a balance between different demands from different societies." (18)

\section{Registration of domain names in China}

Another way the Domain Name System is used to control and "localise" online activities is through the registration of domain names in China.

The global Domain Name System is coordinated from California by the Internet Corporation for Assigned Names and Numbers (ICANN), a not-forprofit private corporation. ICANN delegates the day-to-day maintenance of specific "top-level domain names" (TLD) to other organisations called "registries," such as Verisign (".com") or Public Interest Registry (".org"). In the case of "country-code top-level domain names" (ccTLD, such as ".fr" for France or ".de" for Germany), the delegation is granted to local organisations in accordance with the government of the country or territory. For China, the ".cn" extension is currently delegated to the state-sponsored China Internet Network Information Center (CNNIC).

Like most registries, CNNIC does not provide domain name registration service directly to customers. It just maintains the domain name database for the extension ".cn," and accredits intermediary companies ("registrars") to provide the registration service to website owners.

The Chinese Ministry of Industry and Information Technologies (MIIT, formerly Ministry of Information Industry, MII) regulates this system through the 2004 China Internet Domain Name Regulation. ${ }^{(19)}$ Article 11 states that "any organization that applies for setting up Domain Name Registry or Registrar within the territory of the People's Republic of China shall be approved by MII." Both registries and registrars must set up their servers within the territory of the PRC and employ qualified personnel. Among other technical requirements, both must pledge to "meet other requirements prescribed by Chinese government" (fuhe guojia qita youguan guiding 符合国家其他有关 规定, art.12 §7 and art.14 §7). Moreover, article 27 imposes requirements in terms of domain name content (as translated by CNNIC):

Any of the following contents shall not be included in any domain name registered and used by any organization or individual:
1) Those that are against the basic principles prescribed in the Constitution;

2) Those jeopardize national security, leak state secrets, intend to overturn the government, or disrupt of state integrity;

3) Those harm national honor and national interests;

4) Those instigate hostility or discrimination between different nationalities, or disrupt the national solidarity;

5) Those violate the state religion policies or propagate cult and feudal superstition;

6) Those spread rumors, disturb public order or disrupt social stability;

7) Those spread pornography, obscenity, gambling, violence, homicide, terror or instigate crimes;

8) Those insult, libel against others and infringe other people's legal rights and interests; or

9) Other contents prohibited in laws, rules and administrative regulations.

This control is not limited to the choice of domain names per se but also includes the content of websites. As stated in article 35, "Domain Name Registry and Domain Name Registrars have the obligation to conduct website inspection in coordination with the national governing departments, and to request to suspend or cease the resolution service of the domain name concerned." In other terms, non-compliance with censorship rules can result in the termination of a website's domain name registration in China.

The registration of domain names is also subject to the "Real Name System" that applies to most Internet services in China. Upon registration, applicants must provide their identification card number along with other documents, such as business licence numbers in the case of companies. (20) Such concrete registration requirements often raise concerns because they can restrict access to certain categories of applicants. For example, at the end of 2009, as part of a crackdown against domain names considered illegitimate, a Notification about Further Enhancement of Auditing Domain Name Registration Information (21) effectively limited the registration of ".cn" domain names to Chinese companies by requiring a Chinese business licence number, with retroactive effect. New registrations were therefore impossible for individuals or foreign companies, unless the latter registered through a Chinese subsidiary. Already registered websites were also asked to provide additional documents. This resulted in the end of ".cn" registrations by the American reg-

14. Jack L. Goldsmith and Tim Wu, Who Controls the Internet?: Illusions of a Borderless World, Oxford and New York, Oxford University Press, 2006, Chap. 4.

15. Anupam Chander and Uyen P. Le, "Breaking the Web: Data Localization vs. the Global Internet," Emory Law Journal, UC Davis Legal Studies Research Paper No. 378, 1 April 2014, http://papers. ssrn.com/abstract=2407858.

16. Zoe Fox, "Twitter to Censor Content in Certain Countries," Mashable, 27 January 2012, http://mashable.com/2012/01/26/twitter-to-censor/.

17. See for example the Electronic Frontier Foundation, https://www.eff.org or, in France, La Quadrature du Net https://www.laquadrature.net.

18. "Internet Localization an Inevitable Outcome," Global Times, 20 November 2014, www.globaltimes.cn/content/892881.shtml.

19. Xinxi chanye bu (Ministry of Information Industry), "Zhongguo hulianwangluo yuming guanli banfa" (China Internet Domain Name Regulation), 2004 www.cnnic.cn/ggfw/fwzxxgzcfg/2012/ 201207/t20120720_32419.htm, English translation by CNNIC, www1.cnnic.cn/PublicS/ fwzxxgzcfg/201208/t20120830_35734.htm; initial version published in 2002, www.scio.gov.cn/ zhzc/8/5/Document/1014224/1014224_1.htm.

20. See CNNIC, "Users FAQ, III. How to Register the CN Domain Names," http://www1.cnnic.cn/IS/ CNym/cnymyhfaq/\#3.

21. CNNIC, "Notification about Further Enhancement of Auditing Domain Name Registration Information," 11 December 2009, via Wayback Machine (2012/04/29), https://web.archive.org/ web/20120429195000/http://www.cnnic.net.cn/html/Dir/2009/12/12/5750.htm. 
istrar GoDaddy. (22) As a result of this crackdown and of the subsequent cancellation of domain name registrations by CNNIC, the number of ".cn" domain names plummeted from 13,459,133 at the end of 2009 (23) to 4,349,524 at the end of 2010. (24) Individuals and foreigners were able to register again in 2012 when CNNIC published new Implementing Rules of Domain Name Registration, (25) and CNNIC now lists some 29 overseas registrars on its website. In July 2015 there were 12,251,342 registered ".cn" websites. (26)

To sum up, both domestic and foreign registrars must be accredited by CNNIC to provide registration for ".cn" extensions. Chinese registrars can provide registration services for domain names set up overseas such as ".com," provided they are accredited by the corresponding registries, but they must also get authorisation from the MIIT. Finally, Chinese individuals and companies can get a domain name abroad for their websites via a foreign registrar, in which case their registration would not be subject to Chinese laws, but this might complicate their business relationships by requiring them to use English language and foreign currencies, for instance. In this case, the attraction of the Chinese market is an incentive for foreign registrars to set up offices in China, with Chinese-speaking customer service, in the same time zone as their customers, and servers located in China for faster response. For this, they must seek approval from the Chinese authorities. In other words, the delicate balance between state control and market demand that has characterised the situation of the Chinese media since the 1990 s and early 2000 s $^{(27)}$ is also true for the registration of domain names. Beyond political motives, which may influence a minority of website owners' choices, practical concerns seem to weigh a lot in this balance. Simplicity and speed of service seem sufficient to keep the majority of Chinese website owners in the hands of China-based service providers, and some foreign service providers are willing to set up infrastructure in China, whereas ill-designed administrative rules can also drive more websites abroad, outside of the reach of Chinese institutions.

Indeed, the possibility for customers to register a domain name abroad also puts some pressure on the Chinese authorities. As underlined by the head of a registry operating in China, "If administrative registration requirements are too burdensome to register a'.cn' domain name, Chinese entrepreneurs can choose to register their domain name in '.com'." (28) Of course, such websites registered abroad would still be subject to the threat of domain name blocking, but as seen in terms of the Chinese authorities' interests, this would enable much less refined control over the website's activities than a local registration, which encourages self-censorship and enables daily updates on sensitive issues. It would also mean less local revenue from registrations.

CNNIC itself says that it is seeking "to enhanc[e] competitiveness in the overseas market" through improved quality of service. ${ }^{(29)}$ To improve overseas access and service, CNNIC gradually set up servers in many countries around the world. ${ }^{(30)}$ These servers are able to provide quicker routing information for anyone in a foreign country looking to access Chinese websites. China also hosts mirrors of several of the global "root servers" on Chinese territory, ${ }^{\left({ }^{(31)}\right.}$ which could enhance access to the global Internet for Chinese Internet users.

All in all, the Chinese network is increasingly interconnected with the rest of the world, and at the same time is relatively less dependent on foreign infrastructure. This increasing interconnectedness makes China an important actor and stakeholder in the stability of the global Internet infrastructure. This may also contribute to reducing a perceived, though quite virtual, risk of being excluded from the global Internet by other major actors of the network. (32)

This makes the DNS a very interesting place to observe the articulation between Chinese claims to cyber-sovereignty and their efforts to achieve global connectivity. Since the creation of the ".cn" domain name, this has been a delicate balance to maintain for the institutions that manage the DNS in China, being in charge of the interpretation and implementation of national regulations while working on the practicalities of making the Chinese and foreign networks interoperable.

\section{Defining "cyber-sovereignty" for the Chinese DNS}

\section{0-1998: Relocating and centralising the manage- ment of domain names}

As in many other countries, the Chinese Internet started off mainly within the academic community and in cooperation with foreign counterparts. The academic partnership between Pr. Wang Yunfeng at the Chinese Academy of Sciences (CAS) and Pr. Werner Zorn at Karlsruhe University played a particularly important role in setting up a ccTLD for China. When the ".cn" extension was created at the end of November 1990, the server was located in Karlsruhe, with Pr. Qian Tianbai as an administrative contact in China. It remained this way until 21 May 1995. Then:

With the assistance of Pr. Qian Tianbai and Karlsruhe University, the Computer network information center of CAS finished setting up China's top domain name (CN) servers, after which the .CN domain name servers were no longer located abroad. Qian Tianbai and Qian Hualin were the administrative contact and technical contact respectively. ${ }^{(33)}$

22. Chloe Albanesius, "Go Daddy Cuts Off Chinese Domain-Name Registration," PCmag, 24 March 2010, www.pcmag.com/article2/0,2817,2361779,00.asp.

23. CNNIC, Statistical Report on Internet Development in China, Beijing, January 2010, p. 25.

24. CNNIC, Zhongguo hulianwangluo fazhan zhuangkuang tongji baogao (Statistical Report on Internet Development in China), Beijing, January 2011, www.cnnic.cn/research/bgxz/tjbg/201207/ t20120719_32247.html, p. 25.

25. CNNIC, CNNIC Implementing Rules of Domain Name Registration, 29 May 2012, www1.cnnic. cn/PublicS/fwzxxgzcfg/201208/t20120830_35735.htm.

26. CNNIC, Di 36 ci Zhongguo hulianwangluo fazhan zhuangkuang tongji baogao ( $36^{\text {th }}$ Statistical Report on Internet Development in China), Beijing, July 2015, http://cnnic.cn/hlwfzyj/ hlwxzbg/hlwtjbg/201507/P020150723549500667087.pdf.

27. Yuezhi Zhao, Communication in China: Political Economy, Power, and Conflict, Lanham MD, Rowman \& Littlefield, 2008; Johan Lagerkvist, "In the Crossfire of Demands: Chinese News Portals between Propaganda and the Public," in Jens Damm and Simona Thomas (eds), Chinese Cyberspaces: Technological Changes and Political Effects, London and New York, Routledge, 2006, pp. $42-63$.

28. Interview in Beijing, November 2014 (translated from Chinese).

29. CNNIC, 2013 Annual Report, Beijing, January 2014, https://www.cnnic.cn/gywm/zzkw/cnnicndbg/201401/U020140314621129945634.pdf, p. 9.

30. "CNNIC deployed 30 nodes (Anycast+BCP) with 23 dispersed in mainland China and 7 overseas by the end of 2012, and the number is expected to achieve 50 in 2015," "CNNIC," Centr (Council of European National Top Level Domain Registries), https://centr.org/member/cnnic.

31. There are 13 root servers globally, operated by 12 independent institutions, which provide routing information for first-level domains such as ".com" or ".cn." Many of these servers have in fact several copies, or mirrors, disseminated around the world. Daniel Karrenberg. "DNS Root Name Servers Frequently Asked Questions," ISOC, https://www.isoc.org/briefings/020; see a map of existing root servers on "Root Servers In The World," Google.com, https://www.google.com/maps/d/viewer ?msa=0\&mid=zlG9ajNouOXE.kuelslroMXZQ.

32. Several persons mentioned to me the case of the Iraq war in 2003, when the US allegedly cut off the entire ".iq" domain name, which would have virtually put the entire country's websites offline. In fact the "iq" domain name was never implemented by the US-based corporation that had received delegation for it. In December 2002, the technical contact was incarcerated in the US for money-laundering crimes related to suspected funding of Hamas. The Iraqi domain name was re-delegated by ICANN in 2005 at the request of the new government. See IANA, "IANA Report on Redelegation of the .IQ Top-Level Domain," July 2005, https://wwwiana.org/reports/2005/iq-report-05aug2005.pdf.

33. Werner Zorn, "China's CSNET Connection 1987 - Origin of the China Academic Network CANET," in An Asia Internet History - First Decade (1980-1990), 2013, https://sites.google.com/site/internethistoryasia/book1. 
This was also the time when Internet access became available outside of academic circles with the creation of commercial services. In January 1996, the State Council set up a Leading Panel for Informationisation Work to promote but also regulate this development in a more coordinated manner. As stated by Xue Hong, from then on, "the Internet and the '.CN' domain were subject to governmental administration. Accordingly, the possibility of selfgovernance of the Internet was terminated." (34) Indeed, the Leading Panel issued the Interim Provisions for Administration of Domain Name Registration of Internet in China ${ }^{(35)}$ on 30 May 1997, thereby putting the management of the ".cn" domain names into the hands of the newly-founded CNNIC at the Chinese Academy of Sciences. By 1998, the Leading Panel's regulatory responsibilities were transferred to the new Ministry of Information Industry (MII), ${ }^{(36)}$ which would be further reformed in 2008 to become the Ministry of Industry and Information Technology (MIIT). ${ }^{(37)}$

With these reforms, the technical, daily management of domain names remained in the hands of the CAS, an academic institution (though traditionally close to central power), via CNNIC, while the regulatory power over this system was entrusted to a newly formed and ambitious ministry in charge of the technological modernisation of the country and of the control of the Internet.

Having relocated and recentralised the management of domain names within China by 1998 , the Chinese government was in a better position to voice complaints about the global governance of domain names.

\section{0s: Calls for an intergovernmental model, more compatible with "cyber-sovereignty"}

Public statements from Chinese officials have been quite consistent over the 2000s in defence of the principle of "sovereignty" and of an intergovernmental plot. This translated into repeated criticism against ICANN in its global coordination of the allocation of IP addresses and of top-level domain names. ICANN was founded, like CNNIC, in 1998, at the time of the massive popularisation and commercialisation of the Internet. Also facing the need to take the management of domain names out of the hands of its founder academics, who were no longer able to cope with the exponential growth of websites globally, but also willing to limit its involvement in the matter, the US government pushed for a more privatised system supervised by the Department of Commerce. ${ }^{(38)}$ After some turmoil, ICANN was established as a California-based non-profit corporation with an innovative, evolving governance model called "multi-stakeholder." At ICANN, civil society organisations, businesses involved in the DNS, and individuals can all have a say, as well as government representatives, through complex consensus-building procedures. ${ }^{(39)}$

This system is often criticised for its sustained links with the American government, and for its bias towards lobbies and developed countries, which have more resources to pay experts and to send participants to ICANN conferences around the world. All through the 2000s, Chinese representatives have been vocal in this public criticism and have been advocating for an intergovernmental system under the United Nations, which would allegedly rebalance the decision-making process towards developing countries and the defence of public interest.

In April 2002, Zhao Houlin, then Director of the Telecommunication Standardisation Bureau of the International Telecommunication Union (ITU), a UN organisation, proposed "that ITU could provide support for ICANN and help it to overcome its current difficulties." (40) In November of the same year, the Chinese official press announced that CNNIC and the Internet Society of China had demanded a reform of ICANN. ${ }^{(41)}$ In 2003, at the UNsponsored World Summit for the Information Society (WSIS) in Geneva, Wang Xudong, the Chinese Minister of Information Industry, appealed "for more participation and coordination by intergovernmental organizations." (42) Such attacks against ICANN were reiterated during the 2005 WSIS meeting in Tunis, ${ }^{(43)}$ and China joined other countries at the 2012 World Congress on Information Technology (WCIT) to make a proposal to transfer the management of the DNS to state-level organisations. ${ }^{(44)}$

Other more specific issues also affected the relationship between China and ICANN. From 2001 to 2009, China did not send representatives to ICANN's Governmental Advisory Committee (GAC) until an agreement was reached to refer to Taiwan as "Chinese Taipei." (45)

The Chinese position was articulated in a more comprehensive way in a White Paper on the Internet in China, published by the Information Office of the State Council in 2010. ${ }^{(46)}$ In this report, the Chinese government declared that, "though connected, the Internet of various countries belongs to different sovereignties," and further "holds that the role of the UN should be given full scope in international Internet administration."

\section{Chinese bottom-up participation in the global gover- nance of the DNS}

However, while Chinese government representatives showed reluctance to give credit to ICANN, numerous Chinese engineers and researchers participated and even took leading positions in ICANN's meetings and working groups, as well as in the Regional Internet Registries in charge of the allo-

34. Xue Hong, "Voice of China:A Story of Chinese-Character Domain Names," Cardozo Journal of International and Comparative Law, No. 12, 2004, pp. 559-592.

35. Guowuyuan xinxihua gongzuo lingdao xiaozu bangongshi (State Council Leading Panel for informationisation Work), Zhongguo hulianwangluo yuming zhuce zanxing guanli banfa (Interim Provisions for Administration of Domain Name Registration of Internet in China), 30 May 1997, on Baidu Baike: http://tinyurl.com/owqxprg.

36. For most of these dates, see also the CNNIC's Internet timeline of China, www1.cnnic.cn/ IDR/hlwfzdsj/201306/t20130628_40563.htm.

37. "Ministry of Industry and Information Technology Inaugurated," Xinhua via China.org, 30 June 2008, www.china.org.cn/government/news/2008-06/30/content_15906787.htm.

38. Laura DeNardis, The Global War For Internet Governance, op. cit., p. 62; Marcus Franda, Governing The Internet, London, Lynne Rienner, 2001, pp. 51ff.

39. Milton L. Mueller, Ruling the Root: Internet governance and the taming of cyberspace, Cambridge, MA, MIT Press, 2002; Milton L. Mueller, Networks and states, op. cit.

40. Zhao Houlin, "ITU-T and ICANN Reform," ITU, 17 April 2002, www.itu.int/ITU-T/tsb-director/ituticann/ICANNreform.html.

41. "Zhongguo jianyi gaige ICANN tizhi," (China proposes reform of ICANN system), Renmin ribao haiwai ban, 23 November 2002, www.people.com.cn/GB/paper39/7807/742948.html; CNNIC and Internet Society of China, "Suggestions on ICANN Reform," 26 April 2002, https:// www.cnnic.net.cn/gjj/gjyjydt/200312/t20031213_27765.htm. No traces of this could be found on ICANN website.

42. Wang Xudong, "Strengthening Cooperation, Promoting Development and Moving Towards Information Society," in Daniel Stauffacher and Wolfgang Kleinwächter (eds), The World Summit on the Information Society: Moving from the Past into the Future, New York, United Nations ICT Task Force, 2005, p. 56

43. Milton L. Mueller, "China and Global Internet Governance," in Ronald Deibert, Rafal Rohozinski, and Jonathan Zittrain (eds), Access Contested, Cambridge, MA, MIT Press, 2012, p. 183.

44. Amy Thomson, "China, Russia Resubmit Proposal to Get Web Control," Bloomberg, 12 December 2012, www.bloomberg.com/news/2012-12-12/china-russia-resubmit-proposal-to-get-web-control.html.

45. Rebecca MacKinnon, "China @ ICANN: Thoughts from former CEO Paul Twomey," RConversation, 3 July 2009, http://rconversation.blogs.com/rconversation/2009/07/china-icann-thoughts-fromformer-ceo-paul-twomey.html.

46. Information Office of the State Council, White Paper: The Internet in China, 15 June 2010, http://china.org.cn/government/whitepaper/node_7093508.htm. 
cation of IP addresses, in a more bottom-up manner. A researcher at CNNIC recalls:

More and more people in our work units went to international conferences. There were a lot of participants in the APNIC. We had two representatives from China, one for Taiwan, (...) in total four out of seven were Chinese speakers. We also participated in the working groups to discuss the allocation of IP addresses. We also went to ICANN. It was free of charge so we participated [mainly in the At Large Advisory Committee, open to anyone]. (...) From 2003 to 2006, [Qian Hualin] was a member of the board of directors of ICANN (out of 19 persons). (...) They [government representatives] criticized ICANN because they didn't understand it well and they wanted to keep control. We, at CNNIC, understood it better, so we had a good relationship. ${ }^{(47)}$

The latest report of CNNIC reflects assiduous participation of its members, mainly engineers, in various international instances. ${ }^{(48)}$ As a consequence of this hands-on participation, the critical declarations by Chinese government representatives do not entirely reflect the actual behaviour of China on the operational level, where it has always been represented and involved in the development of policies and technical norms.

This could be explained in part by a difference in agenda between the political and technical communities, with academic engineering staff working on technological development and trying to achieve global interconnection, while political leaders put political control higher in their priorities. To many of my respondents, this is also related to a "pragmatic" approach on the government side, allowing the modernisation of the country without giving in on official principles.

\section{The case of Chinese-character domain names}

\section{Claiming legitimacy over the management of Chi- nese-character domain names}

The technical development and implementation of internationalised domain names can further illustrate how the delicate balance between interconnectedness and sovereignty was maintained throughout the $2000 \mathrm{~s}$.

The initial design of domain names only allowed using Roman characters, excluding any other script such as Cyrillic, Arabic, or Chinese characters. This was criticised very early on as one factor reinforcing the digital divide, forcing entire populations to access the Internet in a foreign script. Besides, many actors in the field had identified those scripts as a potential market to sell more domain names, thus pushing for the adoption of more open technical standards. ${ }^{(49)}$

As early as 1998, various registries had started exploring technical solutions to introduce domain names in Chinese characters, and implemented them on their own networks for trial. (50) For example, by August 2000, Verisign, which at that time managed the ".com," ".org" and ".net" top-level domains, introduced second-level domain names in various scripts including Chinese (which would look like "中文域名.com"). (51) These initiatives raised criticism within the ICANN community because such domain names were not compatible with any other networks, as long as they were not implemented on a global scale. These domain names were not listed in any other directories than the originating company's, and Internet users' web browsers were for the most part not able to decipher these addresses. So these domain names created de facto "intranets," or websites accessible only from a single network.

Hu Qiheng, who at the time was "director of CNNIC's working committee," reacted by claiming that Chinese language domain names should naturally fall under China's oversight. She was not emphasising the need to preserve a global, unique address system, but rather was claiming China's sovereignty over the Chinese-speaking Internet - which extends beyond Chinese territory:

We think as 97.5 percent of the people using Chinese characters live in the mainland and Taiwan, the U.S. government has no right to authorize any company to manage Chinese domain names with Chinese characters. A company shouldn't be allowed to provide Chinese domain name registration services in China without the approval of the Chinese government. (...) Related Chinese departments have protested to the Internet Corporation for Assigned Names and Numbers (ICANN) that Chinese-character domain names are quite different from the ASCII (English) ones, since they have unique (...) cultural and historic implications. ${ }^{(52)}$

Meanwhile, in January 2000 CNNIC had also launched their own "pilot system for Chinese domain names," and the regulation was adapted to accommodate Chinese-character domain names with the publication of the Circular of the Ministry of Information Industry on Management of Chinese Internet Domain Names ${ }^{(53)}$ and the CNNIC Administrative Regulations on Registration of Chinese Domain Names (Trial) (54) in November 2000. According to CNNIC's "Internet timeline of China":

On November 7, 2000, the registration system for Chinese domain names of China Internet Network Information Center (CNNIC) was upgraded in an all-round way, and began to offer the Chinese domain name services with such suffixes as ".cn," “.中国,"“.公司" and ".网络” [respectively ".China," ".com" and ".net"]. (55)

47. Interview in Beijing, November 2014 (translated from Chinese).

48. CNNIC, 2013 Annual Report, op. cit., p. 39.

49. See Milton L. Mueller, Networks and states, op. cit., p. $232 \mathrm{ff}$.

50. Including JPNIC and TWNIC for Japan and Taiwan. ICANN IDN Internal Working Group, Report of the Internationalized Domain Names Internal Working Group of ICANN Board of Directors, ICANN, 28 August 2001, http://archive.icann.org/en/committees/idn/final-report-28aug01.htm.

51. ICANN Board, "ICANN Minutes of Special Meeting," ICANN, 25 September 2000, https://www.icann.org/resources/board-material/minutes-2000-09-25-en; "ICANN Comment on NSI Registry Multilingual Domain Name Testbed," ICANN, 25 August 2000, https://www.icann.org/ news/announcement-2000-08-25-en.

52. Hu Qiheng, "Character Debate: CNNIC Opposes Foreign Firms Registering Chinese-Language Domain Names," China Online, via Wayback Machine (6 December 2000), 3 November 2000, https:/web.archive.org/web/20001206103700/http://chinaonline.com/topstories/001103/1/C00 110208.asp; Also cited in Keith Dawson, The Roving Reporter, 20 January 2001, http://tbtf. com/roving_reporter.

53. Xinxi chanye bu (Ministry of Information Industry), Guanyu hulianwang zhongwen yuming guanli de tonggao (Circular of the Ministry of Information Industry on Management of Chinese Internet Domain Names), Chinalawinfo, 7 November 2000, www.lawinfochina.com/display.aspx?lib= law\&id $=1737 \&$ CGid $=$

54. CNNIC, Zhongwen yuming zhuce guanli banfa (shixing) (Administrative Regulations on Registration of Chinese Domain Names [trial]), China.com.cn, 1 November 2000, www.china.com.cn/chinese/zhuanti/198349.htm.

55. "Internet Timeline of China," CNNIC, 28 June 2012, www1.cnnic.cn/IDR/hlwfzdsj/201306/ t20130628_40563.htm. 
The integration of Chinese domain names into the Chinese DNS was further consolidated in the 2002 China Internet Domain Name Regulation, of which Article 7 states: "Chinese domain name is an integral part of the Domain Names System of China," and in the November 2002 Proclamation on Chinese Domain Name System, ${ }^{(56)}$ which specifically mentioned the three Chinese character top-level domains, ".中国," ".公司" and “.网络." They were mentioned again in the March 2006 revision of the MII Proclamation. ${ }^{(57)}$ In 2008, the MII issued a new proclamation, ${ }^{(58)}$ founding the China Organisational Name Administration Center (CONAC), to "carr[y] out the testbed for Chinese TLD of '.政务' (Government and Government Affairs) and '公益' (Public Interest) and run the registry for '.政务.cn' and '.公益.cn.." (59)

This distinction between top-level domain names ("政务"), which were announced as an experiment, and second-level domain names (".政务.cn"), which were officially implemented, is crucial in terms of coordination with the global Domain Name System. Top-level domain names were implemented in parallel with the global system, not recognised by ICANN, and therefore only resolved by Chinese servers. On the other hand second-level domains were resolved under the ".cn" extension, as part of the global coordinated scheme. In fact, it seems that every website was registered under both the top-level and secondlevel Chinese domain names, which guaranteed interconnection with foreign networks but also contributed to sending confusing signals about Chinese plans for future development of Chinese domain names.

In particular, a 2006 article in People's Daily announcing the new regulation stated, in a somewhat misleading translation, ${ }^{(60)}$ that "[Chinese] Internet users don't have to surf the Web via the servers under the management of the Internet Corporation for Assigned Names and Numbers (ICANN) of the United States." "(61) This contributed to renewed attention and confusion about a program that had actually been initiated several years earlier. Neither was it unprecedented, as similar experiments were conducted in other countries. But these moves were often interpreted as a will to build a Chinese "Intranet." (62 CNNIC maintained that it was only a trial aimed at studying the feasibility of the technologies, and Paul Twomey, then CEO of ICANN, insisted that the announcement was only about second-level domain names. ${ }^{(63)}$

The implementation of a Chinese-character Domain Name System in China had a de facto pre-emptive effect in that it made it impossible for ICANN to assign the related domain names to anyone else without risking an economic, political, and technical conflict with China. ${ }^{(64)}$ At the end of 2009, the MIIT stated that there were 460,000 Chinese domain names in total. By 2012, CONAC had registered 180000 domain names in ".政务" and ".公益." (65)

\section{De facto international cooperation}

In parallel with Chinese officials' calls for sovereignty and their assertiveness in developing domestic schemes, Chinese engineers and scientists from various institutions also participated in collective international initiatives to develop Chinese domain names and ultimately have them implemented within existing Internet governance institutions.

In 2000 ICANN set up an "Internal working group," (66) and in 2001 created an "Internationalized Domain Name Committee." (67) CNNIC soon submitted a proposal on IDN management ${ }^{(68)}$ to the committee, which may have successfully influenced the drafting of technical documents. ${ }^{(69)} \mathrm{Hu}$ Qiheng (founder of CNNIC and the Internet Society of China) subsequently became a member of this committee.

Chinese researchers from CNNIC also teamed up with their Taiwanese, Japanese, and Korean counterparts to find technical solutions to accelerate the implementation of internationalised domain names. In July 2000, they founded a "Joint Engineering Team" (JET), which produced Guidelines for Internationalized Domain Names (IDN) Registration and Administration for Chinese, Japanese, and Korean. ${ }^{(70)}$ The Guidelines were published by the Internet Engineering Task Force (IETF), which has authority to develop technical norms for the Internet globally. The document became a reference point in the drafting of ICANN's 2003 policy on IDNs, ${ }^{(71)}$ which in turn gained clear support from CNNIC, with the following statement:

We support these Guidelines and are pleased to commit to adhere to them in our implementation of IDNs. Recognizing that the Internet community will gain experience with IDN registration policies and procedures as the deployment of IDN services proceeds, we also commit to cooperate with our peer registries and ICANN in good faith to review the Guidelines at regular intervals over the coming years. ${ }^{(72)}$

56. Xinxi chanye bu (Ministry of Information Industry), Hulianwang yuming tixi de gonggao (Proclamation on the Internet Domain Name System)," 22 November 2002, www.tj.cyberpolice.cn/infoAction. do ?act $=$ search\&id= $4028828208 \mathrm{f} 1 \mathrm{c} 9 \mathrm{~b} 00108 \mathrm{ffca} 01 \mathrm{ac0} 107$.

57. Xinxi chanye bu (Ministry of Information Industry), Guanyu tiaozheng Zhongguo hulianwangluo yuming tixi de gonggao (Proclamation on the Upgrading of the Chinese Internet Domain Name System), 1 March 2006, http://baike.baidu.com/view/4764560.htm.

58. Xinxi chanye bu (Ministry of Information Industry), Guanyu Zhongguo hulianwangluo yuming tixi de gonggao (2008 nian) (Proclamation on the Chinese Internet Domain Name System [2008]), 19 March 2008, www.cnnic.cn/ggfw/fwzxxgzcfg/2012/201207/t20120720_32410.htm.

59. "Introduction," CONAC, www.chinagov.cn/english/aboutconac/Introduction/201205/t20120508 _165245.html.

60. Rebecca MacKinnon, "China's New Domain Names: Lost in Translation," CircleID, 28 February 2006, www.circleid.com/posts/chinas_new_domain_names_lost_in_translation.

61. "China Adds Top-Level Domain Names," People's Daily Online, 28 February 2006, http://english. people.com.cn/200602/28/eng20060228_246712.html.

62. For example: "Ever since Chinese characters were introduced on the Net and China took over domain names ending in '.cn,' the regime has been developing a genuine Intranet. Ideogram-based domain names are used to access websites based in China. By typing '.com.cn,' surfers are redirected to the Chinese version of the website concerned. Any Chinese Internet user using ideograms is thus restricted to this Intranet, disconnected from the World Wide Web, and directly controlled by the regime," in "China - The Enemies Of The Internet," Reporters Without Borders, 12 March 2012, http://surveillance.rsf.org/en/china.

63. "ICANN Says China Not Transferring Domain Names onto Single Root," China Tech News, 16 March 2006, www.chinatechnews.com/2006/03/16/3623-icann-says-china-not-transferring-domain-names-onto-single-root.

64. Milton L. Mueller, "China and Global Internet Governance," art. cit., p. 183.

65. "2009 nian 11 yue woguo yuming he IP dizhi shenqing qingkuang," (Report on the Registrations of IP Addresses and Domain Names in China as of November 2009), MIIT, 25 December 2009, www.miit.gov.cn/n11293472/n11293832/n11293907/n11368223/12927911.html; "CONACAchivements," CONAC, 8 May 2012, www.chinagov.cn/english/aboutconac/Achievements/ 201205/t20120508_165247.html.

66. ICANN IDN Internal Working Group, Report Of The Internationalized Domain Names Internal Working Group of ICANN Board of Directors, op. cit.

67. ICANN, "Internationalized Domain Names (IDN) Committee," 28 August 2001, http://archive. icann.org/en/committees/idn/index.html\#Documents.

68. CNNIC, "Management Issues on IDNS: The Prospective [sic] of CNNIC," Computer Network Information Center (Chinese Academy of Sciences), 20 September 2001, www.cnic.cas.cn/ zcfw/cnnic/gjj/gjyj/swyjbg/200909/t20090928_2528877.html.

69. Xue Hong, "Voice of China," art. cit., p. 586; ICANN IDN Internal Working Group, "Discussion Paper on Registry Selection Considerations," ICANN, 13 June 2002, http://archive.icann.org/en/committees/idn/registry-selection-paper-13jun02.htm.

70. Kazunori Konishi, Kenny Huang, Qian Hualin, and Yangwoo Ko, Guidelines For Internationalized Domain Names (IDN) Registration and Administration for Chinese, Japanese, and Korean, IETF, 18 November 2002, http://tools.ietf.org/html/rfc3743.

71. Xue Hong, "Voice of China," art. cit., p. 583; Standards for ICANN Authorization of Internationalized Domain Name Registrations in Registries with Agreements, ICANN, 13 March 2003, http://archive.icann.org/en/meetings/riodejaneiro/idn-topic.htm.

72. Mao Wei, "A Letter of Support for IDN Guidelines from CNNIC," ICANN, 18 June 2003, https://www.icann.org/resources/pages/wei-to-twomey-2003-06-18-en. 
Moreover, in May 2000, the Chinese Domain Name Consortium (CDNC) was established to "coordinate and standardize the Chinese domain names in a nongovernmental way." (73) The CDNC was a joint initiative between CNNIC and equivalent institutions in Taiwan (TWNIC), Hong Kong (HKNIC), and Macau (MONIC), whose researchers would gather two to three times a year, mostly at ICANN meetings.

\section{The new CCTLD and gTLD}

Although China was not a member of the Governmental Advisory Committee during most of the 2000s, it proved willing to take an active part in the issues that mattered most to it, within the framework of ICANN if necessary.

Around 2008, ICANN started to implement internationalised domain names, including Chinese domain names. It became all the more important for China to make sure that its interests would not suffer and at the same time to ensure that Chinese character domain names, already in place within China, would continue working under the new ICANN scheme. From this perspective, the MIIT asked CONAC, in charge of the ".政务" and ".公益" experimental top-level domains and corresponding second-level domains, to coordinate respectively with ICANN and CNNIC. ${ }^{(74)}$ In November 2009, CNNIC officially applied to ICANN for the Chinese language country-code top-level domain (ccTLD) ".中国" (".China"). ${ }^{(75)}$ Internationalised ccTLDs were implemented by ICANN through a "fast-track" process, and ".中国" was delegated in time for the inauguration of the 2010 World Expo in Shanghai. This delegation, in addition to the agreement on the Taiwan issue, may have contributed to the fact that Chinese representatives attended the Governmental Advisory Committee again after 2010.

In 2012, ICANN initiated a vast project of opening of the domain name market with a global bid for the creation and management of new general top-level domains (gTLDs), including internationalised gTLDs. This bid had major consequences in terms of expanding the market and reshuffling the registrar and registry industry, and also raised a number of legal (intellectual property, trademarks) and cybersecurity (cybersquatting, phishing) concerns. The MIIT adapted Chinese regulations in preparation for this change, making it compulsory for proposed Chinese registrars to apply to the MIIT before bidding on ICANN's scheme. ${ }^{(76)}$ Within this controlled framework, Chinese companies were encouraged to apply for new Chinese gTLDs. ${ }^{(77)}$

When the bidding operation closed, 54 Chinese companies and institutions had applied for 39 Chinese-character domain names, but also 50 Romancharacter domain names. Meanwhile, non-Chinese companies had also applied for Chinese domain names. In total, 74 Chinese domain names were proposed by 49 organisations from 15 countries or territories, including (only) 20 Chinese organisations. ${ }^{(78)}$ Some of the proposed Chinese domain names include ".中文网" (".Chinese Internet," TLD Registry), ".我爱你" (".I love you," Zodiac), ".广东" (".Guangdong") and ".天主教" (".Catholic,"Vatican). The two domains ".公司" and ".网络”, previously run by CNNIC, were officially delegated by ICANN and open for public subscription in July 2014. ${ }^{(79)}$

As a result of this privatised bidding process, Chinese institutions were able to secure the management of key Chinese domain names, but foreign companies also invested heavily in this field, betting on the potential growth of the Chinese Internet market. Wang Hao and Liu Fei, researchers at the MIIT's China Academy of Telecommunication Research, compare this transformation of the domain name market with the "Spring and Autumn period" of Chinese history, with a multitude of little territories administered by local leaders. They believe that it may evolve towards a "Warring States Period" as competition eliminates smaller players and enables big transnational companies such as TLD Ltd., Verisign, Neustar, Afilias (registries) or GoDaddy, Tucows (registrars) to gain control over a large part of the new domain name landscape. ${ }^{\left({ }^{80}\right)}$

\section{Advancing China's interests within the multi- stakeholder model of governance}

This state of affairs in which private interests play an important role in the management of (Chinese) domain names is important to understanding the position of Chinese officials in more recent years, in which domestic control and sovereignty have been highlighted at the same time as a de facto acknowledgement of the global, multi-stakeholder Internet governance scheme.

For example, Wang Xiujun, Vice Minister of the State Internet Information Office, commented on the development of new Chinese domain names with the following words:

First, China must maintain network security while vigorously promoting Internet development; second, rights and obligations shall be kept in balance; third, the development of network culture must be guided by core socialist values; and fourth, international exchange and cooperation in the Internet field must be strengthened based on the principle of multi-stakeholder, democracy and transparency. ${ }^{(81)}$

\section{Since 2010: Enhanced cooperation of Chinese officials with ICANN}

Indeed, the cooperation between ICANN and CNNIC has considerably improved in recent years. All partners and observers see the recent change of attitude of China as a pragmatic move to advance its interests and make its voice heard, in particular in the context of the development of new general top-level domains and of Chinese domain names.

Chinese representatives started to once again attend the Governmental Advisory Committee at ICANN in 2010. From 2011 to 2013, Li Xiaodong (now

73. "Internet Timeline of China," art. cit; Also see, "Introduction about Chinese Domain Name Consortium," CDNC, 19 May 2000, www.cdnc.org/english/introduction/index.html.

74. Gongye he xinxihua bu (Ministry of Industry and Information Technology), Guanyu tongyi zhongyang bianban jiguan fuwuju shiye fazhan zhongxin chengwei .zhengwu .gongyi yuming zhuce guanli jigou de pifu (Notice on the Approval of CONAC to Become the Registry for ".Zhengwu" and ".Gongyi" Domain Names), 27 March 2008, www.miit.gov.cn/n11293472/ n11505629/n11506554/n11517240/n11919295/n12051692/12052000.html.

75. "CNNIC zhengshi dijiao '.zhongguo' yuming guoji shenqing" (CNNIC Officially Opens International Registration for ".Zhongguo" Domain Name), MIIT, 16 November 2009, www.miit.gov.cn/ n11293472/n11293877/n12860691/n12860837/n12861706/12882385.html.

76. Gongye he xinxihua bu (Ministry of Industry and Information Technology), Guanyu hulianwang tongyong dingjiyu shenqing youguan wenti de tonggao (Circular on Questions Regarding the Registration of GTLDs), 1 March 2012, http://dgj.miit.gov.cn/n11293472/n11295276/ n11297683/14482562.html.

77. Zhou Wenlin, "Xin tongyong dingji yuming shenjing damen dakai - Guonei qiye ying jiji buju" (New gTLDs Applications Are Open - Chinese Companies Must Take Action), Xinhua via MIIT, 5 January 2012, www.miit.gov.cn/n11293472/n11293832/n11293907/n11368277/14417531 .html.

78. Wang Liang and Liu Fei, "Tongyong dingjiyu jinru chunqiu zhanguo shidai" (gTLDs Entering a Spring and Autumn Period), MIIT, 28 February 2013, www.miit.gov.cn/n11293472/ n11293832/n15214847/n15218234/15223845.html.

79. CNNIC, "'.gongsi' '.wangluo' chuangxin kaituo zhong dili qianxing" (Making Progress amid Difficulties with Ground-breaking Innovation on ".Gongsi", ".Wangluo"), Yuming cheng, 1 September 2014, http://news.domain.cn/html/yumingzixun/2014/0901/36576.html.

80. Wang Hao and Liu Fei, "Tongyong dingjiyu jinru chunqiuzhanguo shidai," art. cit.

81. "Chinese GTLD Promotion Program Opens a New Era of Chinese Internet," CNNIC, 22 July 2014, www1.cnnic.cn/AU/MediaC/rdxw/2014/201407/t20140722_47465.htm. 
CEO of CNNIC) was appointed vice-president of ICANN in charge of Asian affairs. CNNIC announced his nomination with the following comment:

[It] not only signifies that the reputation of Chinese Internet experts has been increasingly recognized by the international Internet organizations, but also indicates the increasingly expanding influence of China in the field of Internet and the constantly-enhanced soft power in participating in the international Internet governance. ${ }^{(82)}$

Furthermore, China hosted an ICANN meeting in Beijing in April 2013. At the same time, CNNIC became one of the "emergency back-end registry operators" (EBERO), which are ready to take over the role of a registry in case of a failure. In August of the same year, ICANN set up an engagement centre in Beijing, hosted within the premises of CNNIC at the Chinese Academy of Sciences. ${ }^{(83)}$ Fadi Chéhadé, president of ICANN, made several visits to China in 2014. ${ }^{(84)}$

This does not affect China's control over the circulation of information on Chinese territory. On the contrary, it tends to enhance the Chinese actors' control of critical infrastructure. Yu-chuang Kuek, ICANN's vice president and managing director for its Asia Pacific hub in Singapore, says:

The Chinese government's approach is fairly pragmatic. They are willing to have a conversation and to collaborate to make sure the Internet works. (...) If we come back to the structure of the Internet, one layer is made of contents, with applications, with issues of data protection, privacy, censorship etc. The bottom layer is made of infrastructures, with the undersea cables, ISP peering etc. ICANN has a role in the middle layer, called the logical layer, to ensure interoperability [through various technical protocols]. The Chinese position [of openness] applies to the logical layer only. ${ }^{(85)}$

This increasing cooperation is in part motivated by a need to provide better, more reliable, secure, user-friendly service to Chinese Internet users and businesses, which CNNIC has also been pushing for. The need to offer better representation to Chinese Internet users also strikes a chord among ICANN representatives. As many stakeholders, including EU countries and developing countries, have been advocating for more inclusiveness and accountability, and in general have asked ICANN to be more responsive to requests, they are striving to improve the institution's legitimacy, especially in the developing world. China is a priority target in this agenda. According to Song Zheng, head of the Beijing engagement centre:

China is the largest Internet country and it is rapidly growing. Without China, we cannot call ourselves inclusive. We have about 100 new gTLD applicants from China. We must provide localised service for them. Now in our Singapore hub, we have over 20 staff who can provide service in Chinese. It is a big progress. (...) We want to make China an important part of ICANN affairs. ${ }^{(86)}$

\section{A more dominant position within the multi-stake- holder system?}

As they are calling for more investments and cooperation with ICANN, current official representatives tend to downplay the importance of the critical declarations of the last decade and now seem to endorse the multi- stakeholder model of governance. For example, at a panel at the Bo'Ao Asia Forum held in April 2014, Fu Cong, a representative of China's Ministry of Foreign Affairs, declared that "China does not oppose the multi-stakeholder approach in Internet Governance." (87)

The rhetoric used by Chinese representatives also shows that Chinese leaders have realised that the Chinese Internet has reached a critical size, which may enable them to weigh in on the decision-making process, not only through government representatives, but also through the business and user communities, who can now afford more intense participation in ICANN and other fora. There are more and more Chinese participants in ICANN meetings, especially from the private sector. In other words, there is no point fighting the multi-stakeholder model if China can benefit from this system.

In 2014, the US government announced that it intended to withdraw from its role as a supervisor of the "IANA functions" performed by ICANN (including the management of the top-level domain name data in the "root zone database"). In the current scheme, the National Telecommunications and Information Administration (NTIA), located within the American Department of Commerce, is the authority that awards the contract to perform the IANA functions. It plays a day-to-day clerical role in verifying that the relevant policies and procedures are followed by ICANN in processing change requests to the root zone database, and it periodically organises performance reviews. The withdrawal of the US government from this "stewardship" role raises crucial political issues of accountability and independence along with procedural challenges. At the time of writing, the consultation process for this reform is underway. Chinese representatives take part in the discussion, notably with Li Xiaodong as a member of the IANA Stewardship Transition Coordination Group. ${ }^{(88)}$

Meanwhile, the management of domain names in China was concentrated again with the creation of the Central Leading Group for Internet Security and Informatisation ${ }^{(89)}$ at the beginning of 2014 and the transfer of CNNIC from the Chinese Academy of Sciences to the Cyberspace Administration of China (CAC), ${ }^{(90)}$ which replaces the State Internet Information Office, a body formed in 2011 under the State Council. The Chinese Internet is now overseen by Lu Wei, the head of the CAC, in a direct, centralised, and personalised way ${ }^{(91)}$ and it seems that domain names are perceived as a key

82. "Xiaodong Li, Researcher of CNIC, Serves as Vice President of ICANN," CNNIC, 8 December 2011, www1.cnnic.cn/IC/Events/201209/t20120917_36221.htm.

83. ICANN, "ICANN Engagement Center to Open in Beijing," TMCnet, 8 April 2013, http://tech news.tmcnet.com/news/2013/04/09/7049177.htm.

84. Song Zheng, "Chinese New Year in Beijing with ICANN President," ICANN, 17 February 2014, https://www.icann.org/news/blog/chinese-new-year-in-beijing-with-icann-president.

85. Interview on Skype, October 2014.

86. Interview in Beijing, November 2014.

87. Cited in Song Zheng, "Bo'Ao Asia Forum," ICANN APAC Newsletter, April 2014, http://gallery. mailchimp.com/818d573897ed5ea25ee71ebc1/files/Bo_Ao_Asia_Forum.pdf.

88. "IANA Stewardship Transition Coordination Group Members," ICANN, https://www.icann.org/resources/pages/coordination-group-2014-06-17-en (accessed on 16 January 2015).

89. Rogier Creemers, "Central Leading Group for Internet Security and Informatization Established," China Copyright and Media, 1 March 2014, http://chinacopyrightandmedia.wordpress.com/ 2014/03/01/central-leading-group-for-internet-security-and-informatization-established.

90. State Council, Guanyu shouquan guojia hulianwang xinxi bangongshi fuzehulianwang xinxi neirong guanli gongzuo de tonggao (Notice Concerning Empowering the Cyberspace Administration of China to Be Responsible for Internet Information Content Management Work), trans. Rogier Creemers, China Copyright and Media, 26 August 2014, https://chinacopyrightandmedia.wordpress.com/2014/08/26/notice-concerning-empowering-the-cyberspace-administration-of-chinato-be-responsible-for-internet-information-content-management-work.

91. Paul Mozur and Jane Perlez, "Gregarious and Direct: China's Web Doorkeeper," NYTimes.com, 1 December 2014, www.nytimes.com/2014/12/02/world/asia/gregarious-and-direct-chinas-webdoorkeeper.html?_r=0. 
issue in this field. However, Lu Wei himself has attended several ICANN meetings, which is generally perceived as an acknowledgement of existing institutions. It seems that concentrated management and enhanced cooperation with global Internet governance institutions are two sides of the same coin.

\section{Conclusion}

For China, the management of domain names has clear and strong implications in terms of information control and digital sovereignty. It is at the heart of Internet censorship through the rules of domain name registration within China, and through blocking access to websites hosted abroad. However, the history of the DNS in China suggests that metaphors such as the "Great Firewall" or the "Chinese Intranet" can be somewhat misleading. Indeed they do not help understand the fine line that the Chinese authorities have been drawing between international connectivity, which is indispensable to the modernisation of China, and selective control of online content, which is perceived as essential to political stability. Creating a separate network within China may have been the dream of some Chinese leaders, particularly at the beginning of Internet development, but it has so far proved unfeasible both technically and politically.

Instead, the concept of "digital sovereignty" now translates into a set of domestic regulations and practices that help guarantee the compliance of companies and individuals who operate on Chinese territory and cater to the Chinese market (this is part of what MacKinnon calls "networked authoritarianism" (92)). In fact, practical constraints such as the need to provide localised, user-friendly service are strong incentives even for foreign companies to set up local infrastructure and submit themselves to Chinese control. But there are likewise limits to the administrative burdens that the authorities can impose on website owners and DNS service providers (such as real-name registration requirements), for they may turn to overseas services, which would cut corresponding revenues and reduce the fine-tuning of control.

This produces a form of "localised" Internet, rather than a separate Internet. In that sense China pioneered the use of the DNS as a technical answer to the political challenge brought to national jurisdictions by the transnational character of online speech. It is one of the earliest and most significant examples of what has become a global trend of restricting access of Internet users to certain types of content depending on their location, for various legal, religious, or moral reasons, and with various degrees of legitimacy. It adds up to other types of localising measures aimed at providing tailored content to Internet users, with or without their knowledge, and in any case it contributes to undermining the myth of a unique, global Internet where every individual in the world would have equal access to the same content.

This strategy, in tension between domestic control and international connectivity, has direct consequences in the engagement of China with ICANN and other institutions in charge of the DNS at the global level. While Chinese representatives consistently expressed criticism of the multi-stakeholder scheme, there were almost always Chinese engineers in key working groups and meetings. China was thus able to defend its interests pragmatically without giving up on its core principles of cybersovereignty.

The case of the development of domain names in Chinese characters, such as ".中国" and ".中文网," illustrates well how China's position has evolved from the claim of Chinese sovereignty over the Chinese language Internet to active participation in working groups for the development of necessary technical standards, and to a strategy for gaining an upper hand within the new, largely privatised global scheme. After a decade of rapid growth, the Chinese Internet has reached a critical scale in terms of users, businesses, and technical experts, which enables the Chinese to weigh in more on multistakeholder discussions and above all to attract foreign businesses within the reach of the Chinese jurisdiction, where there is by far the largest market for Chinese language domain names.

In a 2012 article, Milton L. Mueller suggested that this "cybernationalist" position was not a stable, early-defined strategy, but rather an "improvised response to the contradictions of the socialist market economy." (93) Indeed, various episodes of sudden restriction or opening of the Chinese Domain Name System suggest that these issues raise debates within the Chinese leadership itself. The variety of actors involved, from political leaders to academic researchers and to business owners, may also explain some of the nuances of the Chinese position.

Over the long term, the Chinese leadership has progressively concentrated the management of the DNS closer to the central authorities, and it has become more confident about China's capacity to acquire a more dominant position globally, not only through the government, but also through private actors and individuals. This self-confidence has allowed China to adopt a somewhat more cooperative attitude in the multi-stakeholder framework in recent years. The participation of high-ranking individuals in ICANN meetings is generally interpreted as a sign of good will, but it may also indicate that the Chinese authorities consider these issues highly sensitive and deserving of close attention at the highest level.

\section{Séverine Arsène is a researcher at CEFC and Chief Editor of China Perspectives. \\ CEFC, 20/F Wanchai Central Building, 89 Lockhart Road, Wanchai, Hong Kong.}

92. Rebecca MacKinnon, "China's 'Networked Authoritarianism,"' Journal of Democracy, Vol. 22, No. 2, 2011, pp. 32-46.

93. Milton L. Mueller, "China and Global Internet Governance," art. cit., p. 191 